Respiratory Infection Group, Nottingham City Hospital, Nottingham NG5 1PB, UK

J Macfarlane

R Macfarlane

Department of Radiology

D Rose

Department of Respiratory Medicine, University of Nottingham and

Sherrington Park Medical Practice, Nottingham NG5 2EJ, UK

W Holmes

Arnold Health Centre, Arnold, Nottingham NG5 7BQ, UK

P Gard

Department of Microbiology and Public Health

Laboratory, University Hospital, Nottingham NG7 2UH, UK

$\mathrm{V}$ Weston

Laboratory for Respiratory Bacterial Infections, National Public Health Institute, Department in Oulu, 90101 Oulu, Finland

M Leinonen

Chlamydia Laboratory P Saikku

Department of Microbiology \& Immunology,

University of Leicester, Leicester LE1 9HN, UK

S Myint

*Current address: c/o Anti-infectives TU, SmithKline Beecham Pharmaceutics, Harlow, Essex CM19 5AW, UK

Correspondence to: Dr J Macfarlane john.macfarlane $a$ nottingham.ac.uk

\title{
Prospective study of the incidence, aetiology and outcome of adult lower respiratory tract illness in the community
}

\author{
J Macfarlane, W Holmes, P Gard, R Macfarlane, D Rose, V Weston, M Leinonen, \\ P Saikku, S Myint*
}

Abstract

Background-Acute lower respiratory tract illness in previously well adults is usually labelled as acute bronchitis and treated with antibiotics without establishing the aetiology. Viral infection is thought to be the cause in most cases. We have investigated the incidence, aetiology, and outcome of this condition.

Methods-Previously well adults from a stable suburban population consulting over one year with a lower respiratory tract illness were studied. For the first six months detailed investigations identified predetermined direct and indirect markers of infection. Evidence of infection was assessed in relation to presenting clinical features, indirect markers of infection, antibiotic use, and outcome.

Results-Consultations were very common, particularly in younger women (70/ 1000 per year in previously well women aged 16-39 years), mainly in the winter months; 638 patients consulted, of whom 316 were investigated. Pathogens were identified in $173(55 \%)$ cases: bacteria in 82 (Streptococcus pneumoniae 54, Haemophilus influenzae 31, Moraxella catarrhalis 7), atypical organisms in 75 (Chlamydia pneumoniae 55, Mycoplasma pneumoniae 23), and viruses in 61 (influenza 23$)$. Seventy nine (24\%) had indirect evidence of infection. Bacterial and atypical infection correlated with changes in the chest radiograph and high levels of $\mathrm{C}$ reactive protein but not with (a) the GP's clinical assessment of whether infection was present, (b) clinical features other than focal chest signs, and (c) outcome, whether or not appropriate antibiotics were prescribed.

Conclusions-Over $50 \%$ of patients have direct and/or indirect evidence of infection, most commonly bacterial and atypical pathogens, but the outcome is unrelated to the identified pathogens. Many patients improve without antibiotics and investigations do not help in the management of these patients. GPs can reassure patients of the causes and usual outcome of this self-limiting condition.

(Thorax 2001;56:109-114)

Keywords: adult lower respiratory tract illness; acute bronchitis; pathogens; general practice

Episodes of acute respiratory illness are the most common reason for consulting a general practitioner (GP) in the UK. ${ }^{1}$ Many are called "acute bronchitis" and are labelled as infection, with little knowledge of the true aetiology, and are treated with antibiotics ${ }^{2}$ despite numerous studies demonstrating little overall benefit. ${ }^{3}$ No studies have investigated in detail the causes of community acquired lower respiratory tract illness (LRTi) or acute bronchitis, although viral infections are generally thought to be the most important cause. This makes it difficult to provide evidence based advice about management strategies for this common condition.

We describe a year long prospective study of the incidence, aetiology, and outcome of LRTi in a defined population of previously well adults.

\section{Methods}

Ten GPs from two practices serving a suburban population of 14453 adults aged 16 and over recorded structured data on all previously well adults consulting with acute LRTi (defined in

- Previously well patients were defined as not under supervision or management for an underlying disease-for example, patients with asthma, chronic obstructive pulmonary disease, heart disease, and diabetes were not included.

- Lower respiratory tract illness (LRTi) required all of:

(a) an acute illness present for 21 days or less;

(b) cough as the cardinal symptom;

(c) at least one other lower respiratory tract symptom (sputum production, dyspnoea, wheeze, chest discomfort/pain);

(d) no alternative explanation-for example, not sinusitis, pharyngitis, or a new presentation of asthma.

Box 1 Definitions used. ${ }^{4-6}$ 
A. Specimens obtained by the research nurse (number (\%) of that investigation collected from the $\mathbf{3 1 6}$ patients)

- Two throat swabs for bacterial and viral studies $(316,100 \%)$.

- Blood for serology initially (315, 99\%) and about 10 days and one month later (triple or paired serum samples in 300).

- Sputum (273, 86\%), assisted by saline nebulisation when necessary.

- Chest radiograph at the City Hospital and reviewed "blind" by our radiologist $(289,92 \% ; 232,80 \%$ within 3 days; and $287,99 \%$ within 5 days).

\section{B. Definition of direct evidence of infection}

- Isolation of a bacterial respiratory pathogen from diluted sputum.

- At least a fourfold rise in antibody titre to viral and atypical pathogens.

- Detection of Chlamydia pneumoniae IgM in serum.

- Detection of pathogens in throat swabs by culture (for influenza viruses $A$ and $B$, parainfluenza, adenovirus and RSV) or gene amplification (for coronavirus, human rhinovirus, Mycoplasma pneumoniae and $C$ pneumoniae).

- At least a threefold rise in antibody titres to Haemophilus influenzae and Moraxella catarrhalis.

- Pneumococcal infection required detection of one or more of sputum pneumococcal capsular antigen, serum pneumococcal immune complexes (ICs) including pneumolysin-specific IC (in a titre of $\geqslant 100$ ), pneumococcal surface antigen IC (titre $\geqslant 100$ ), C-polysaccharide-specific IC (titre $\geqslant 150$ ), or a twofold or greater rise in pneumolysin and C-polysaccharide-specific antibodies. $^{10}$

\section{Definition of indirect evidence of} infection included one or both of:

- The presence of chest radiographic changes consistent with infection.

- High C reactive protein (CRP) of $50 \mathrm{mg} / 1$ or more.

\section{Patient groupings used in the} analysis included:

- Group 1: evidence of bacterial and/or atypical infection (and who consequently might be expected to benefit from antibiotics).

- Group 2: evidence of viral infection only or no direct evidence of infection (in whom antibiotic treatment would theoretically be unhelpful).

Box 2 Specimens obtained, the definition of infection used, and infection groupings used for the analysis. box 1) between October 1997 and September 1998. ${ }^{4-6}$ The practices were experienced in identifying and studying patients with acute respiratory illnesses, having participated in several previous studies. The GPs recorded whether they felt their patient had an infection which might respond to antibiotics as: "definitely yes"; "probably yes"; "probably no"; and "definitely no". The management of the illness was left to the doctor's discretion; the doctor did not ask the patient to return for another consultation. Patients saw their GP again only if the patient requested a second consultation. Patients' practice records were tracked and those reconsulting for the same illness within a month were identified. The study was approved by the Nottingham City Hospital ethics committee.

DETAILED INVESTIGATION STUDY

During the first six months of the study a research nurse was available at three quarters of surgeries. Patients eligible to enter the detailed investigation study and willing to participate visited the nurse immediately after their GP consultation.

Samples were handled and investigated as previously described. ${ }^{6-10}$ Criteria for direct and indirect evidence of infection and infection groupings were defined at the outset of the study (box 2).

Statistical significance was assessed using the $\chi^{2}$ test for categorical variables and the Student's $t$ test for continuous variables.

\section{Results}

Community acquired LRTi was recorded in 638 patients during the year (median age 43 years; 25 th and 75 th percentiles, 31 and 59 years; $60 \%$ female). A $10 \%$ random sample of 1383 notes audited by the research nurses showed that $81 \%$ of adults in the practices were "previously well", using the definition in box 1 . Hence, the overall incidence was 44/1000 adult population per year and 54/1000 "previously well" adults (table 1). There was a marked seasonal variation with 524 patients $(82 \%)$ being seen between October and March; 329 (52\%) received oral antibiotics - amoxycillin (272), macrolide (44), quinolone (5), cephalosporin (3), tetracycline (1), other (1), not known (3). Over the six winter months 316 of the 524 patients were investigated. Two hundred and eight patients were not studied for the following reasons: research nurse not available (109), patient unable or unwilling (95), practice too busy (2), temporarily resident (2). Investigated patients were more likely to have systemic symptoms, other lower respiratory symptoms, and to be prescribed antibiotics (table 2).

\section{RESULTS IN THE 316 PATIENTS INVESTIGATED}

Direct evidence of infection

Full investigations were obtained on nearly all consenting patients (box 2). Pathogens were identified in 173 patients (55\%) with 130 having evidence of one pathogen, 39 with two pathogens, and four having three pathogens. Bacterial pathogens were found in 82 patients, atypical pathogens in 75 (all diagnosed 
Table 1 Incidence of lower respiratory tract illness (LRTi) expressed as number of cases per 1000 population for different age groups and sex for the total practice population and the proportion that fulfilled the definition of being "previously well"

\begin{tabular}{|c|c|c|c|c|c|c|}
\hline \multirow[b]{2}{*}{ Age group } & \multicolumn{3}{|c|}{ Total population } & \multicolumn{3}{|c|}{$\begin{array}{l}\text { Previously well } \\
\text { population }\end{array}$} \\
\hline & Total & Men & Women & Total & Men & Women \\
\hline $16-39$ & 50 & 36 & 64 & 55 & 40 & 70 \\
\hline $40-59$ & 45 & 42 & 49 & 53 & 49 & 57 \\
\hline $60+$ & 35 & 27 & 41 & 56 & 45 & 64 \\
\hline All ages & 44 & 36 & 52 & 54 & 44 & 64 \\
\hline
\end{tabular}

serologically), and viral pathogens in 61 including influenza A (23), coronavirus (16), rhinovirus (13), influenza B (4), respiratory syncytial virus (3), and adenovirus in 2 (table 3).

Indirect evidence of infection

Seventy nine patients (24\%) had indirect evidence of infection. Forty eight chest radiographs $(17 \%)$ showed changes consistent with infection; 17 (6\%) fulfilled the British Thoracic Society definition of radiographic pneumonia. Fifty patients $(16 \%)$ had a high CRP level (which we defined as $50 \mathrm{mg} / \mathrm{l}$ or over).

There was a significant relationship between chest radiographic changes and high CRP levels; of 48 patients with chest radiographic changes consistent with infection, $19(40 \%)$ had a high CRP level compared with 26/241 (11\%) who had no changes consistent with infection $(\mathrm{p}<0.0005)$. Of the 17 patients with radiographic pneumonia, $11(65 \%)$ had a high CRP level.

RELATIONSHIP BETWEEN DIRECT AND INDIRECT EVIDENCE OF INFECTION

The 137 patients in group 1 (bacterial/atypical pathogens identified) more commonly had indirect evidence of infection than the 179 patients in group 2 (viral/no pathogens identified). High CRP levels were found in 31/137 $(23 \%)$ of group 1 compared with $19 / 179$ $(11 \%)$ of group $2(p=0.004)$. Chest radiographic changes consistent with infection occurred in 32/129 (25\%) of patients in group 1 who underwent radiography and 16/160 $(10 \%)$ of group $2(\mathrm{p}=0.0008)$.

When specific bacterial and atypical pathogen groups were analysed individually within group 1, only $C$ pneumoniae was not associated with indirect evidence of infection.

CLINICAL FEATURES AND CLINICAL ASSESSMENT Clinical features were similar for the two groups (data not shown) except that patients in group 1 more often had focal signs on chest examination $(31 / 136 ; 23 \%)$ than those in group $2(17 / 179 ; 9 \%)(\mathrm{p}=0.001)$.

There was no relationship between the GPs' clinical assessment that an infection warranting antibiotics was present and bacterial or atypical infection being subsequently found (table 4).

OUTCOME AND RELATION TO EVIDENCE OF INFECTION AND ANTIBIOTIC USE

Reconsultation for the same illness within a month was common, with nearly one in five patients arranging to see their GP again. Direct or indirect evidence of infection at first presentation did not relate to reconsultation, neither did antibiotic use when analysed for groups 1 and 2 as a whole nor for individual pathogens (table 5).

Of the 75 patients who had one or more atypical pathogens identified, $43(57 \%)$ were prescribed an antibiotic (amoxycillin (34), erythromycin (7), a quinolone (2)). The outcome was not related to receiving an antibiotic to which an atypical infection should respond - that is, erythromycin or a quinolone.

\section{Discussion}

This study confirms that consultations for acute LRTi in adults are very common, particularly for younger women, probably reflecting a higher consulting habit for this group.

CASE DEFINITIONS: LRTi AND “ACUTE

BRONCHITIS"

Studies into acute respiratory illnesses have long struggled to define episodes in primary care $^{6}$ where GPs almost invariably manage and prescribe without investigations.

We have defined a term "acute lower respiratory tract illness" ${ }^{9-6}$ similar to that used in previous studies. ${ }^{11}{ }^{12}$ It approximates to the various definitions of "acute bronchitis" used before $^{6}$ but has the important advantage of being definable, reproducible, and readily usable within a routine GP consultation.

MEASURING OUTCOME OF ACUTE RESPIRATORY INFECTIONS

Defining a clinically relevant and easily measurable end point for many symptom complexes in primary care is difficult. ${ }^{13}$ We chose reconsultation as an outcome for this condition because it is: (a) common, with an incidence of 20-30\%, (b) important, causing inconvenience to patients and their doctors and increased use of health service resources, (c) easy to measure accurately, and (d) related to persisting, bothersome symptoms. ${ }^{245781415}$ It therefore has more meaning than minor differences in recovery rates recorded on symptom diaries.

\section{STUDY LIMITATIONS}

The study has a number of limitations. We were only able to investigate about two thirds of the patients who consulted during the winter period. Although demographic features were very similar, systemic and lower respiratory symptoms and antibiotic use were less common in the group not investigated in the winter, as were systemic symptoms in the summer group, suggesting milder illness. Our results may not be representative of the whole group but it is unlikely that we missed much serious illness.

Our GP practices may not be typical as they are experienced in research into LRTi and antibiotic use. The level of antibiotic prescribing was lower than typical levels in LRTi. ${ }^{2}$ It is possible that the patients in the practices consulted less frequently than average for minor lower respiratory symptoms, but this 
Table 2 Demographic and clinical features of patient groups

\begin{tabular}{|c|c|c|c|}
\hline & $\begin{array}{l}\text { Patients studied in detail } \\
\text { over winter } 6 \text { months }\end{array}$ & $\begin{array}{l}\text { Patients not entered into } \\
\text { detailed study over winter } \\
6 \text { months }\end{array}$ & $\begin{array}{l}\text { Patients seen during summer } \\
6 \text { months }\end{array}$ \\
\hline No & 316 & 208 & 114 \\
\hline Sex (no of women) & $184(58 \%)$ & $130(63 \%)$ & $71(62 \%)$ \\
\hline \multicolumn{4}{|l|}{ Age (years) } \\
\hline Median (range) & $46(16-84)$ & $40(16-89)$ & $45(16-80)$ \\
\hline Interquartiles & 34,59 & 29,56 & 31,59 \\
\hline \multicolumn{4}{|l|}{ Smoking } \\
\hline Never & $158(50 \%)$ & $115(56 \%)$ & $60(54 \%)$ \\
\hline Ex-smoker & $73(23 \%)$ & $32(16 \%)$ & $23(20 \%)$ \\
\hline Current & $84(27 \%)$ & $57(28 \%)$ & $29(26 \%)$ \\
\hline \multicolumn{4}{|l|}{ Duration of symptoms (days) } \\
\hline Median & 7 & 7 & 7 \\
\hline Interquartiles & 4,14 & 4,10 & 5,10 \\
\hline \multicolumn{4}{|l|}{ Cough } \\
\hline Dry & $42(13 \%)$ & $45(22 \%)$ & $20(18 \%)$ \\
\hline Clear sputum & $45(14 \%)$ & $45(22 \%)$ & $14(12 \%)$ \\
\hline Discoloured sputum & $226(72 \%)$ & $117(56 \%)$ & $80(70 \%)$ \\
\hline Wheeze $\left({ }^{\star} \mathrm{p}=0.006\right)$ & $127(40 \%)^{\star}$ & $59(28 \%)^{\star}$ & $50(44 \%)$ \\
\hline Shortness of breath $\left({ }^{\star} \mathrm{p}=0.0003\right)$ & $101(32 \%)^{\star}$ & $37(18 \%)^{\star}$ & $30(26 \%)$ \\
\hline Chest pain $\left({ }^{\star} \mathrm{p}=0.0004\right)$ & $134(42 \%)^{\star}$ & $57(27 \%)^{\star}$ & $40(35 \%)$ \\
\hline Sore throat & $203(64 \%)$ & $121(61 \%)$ & $67(59 \%)$ \\
\hline Systemic $\left({ }^{\star} \mathrm{p}=0.04,+\mathrm{p}<0.001\right)$ & $161(51 \%)^{\star} \dagger$ & $90(43 \%)^{\star}$ & $38(33 \%) \dagger$ \\
\hline Temperature $\geqslant 37.5^{\circ} 0 \mathrm{C}$ & $46(15 \%)$ & Not done & Not done \\
\hline Pulse $\geqslant 100 / \min ^{\star \star}$ & $11(4 \%)$ & Not done & Not done \\
\hline \multicolumn{4}{|l|}{ Respiration rate r $^{\star \star}$} \\
\hline$\geqslant 20 / \mathrm{min}$ & $116(46 \%)$ & Not done & Not done \\
\hline$\geqslant 30 / \mathrm{min}$ & $4(2 \%)$ & Not done & Not done \\
\hline \multicolumn{4}{|l|}{ Chest examination } \\
\hline Clear & $194(62 \%)$ & $145(70 \%)$ & $71(63 \%)$ \\
\hline General & $73(23 \%)$ & $38(18 \%)$ & $28(25 \%)$ \\
\hline Focal & $48(15 \%)$ & $23(11 \%)$ & $14(12 \%)$ \\
\hline Antibiotic prescribed $\left({ }^{\star} \mathrm{p}=0.001\right)$ & $181(57 \%)^{\star}$ & $88(42 \%)^{\star}$ & $60(53 \%)$ \\
\hline
\end{tabular}

Unless otherwise indicated, data were available on $98 \%$ or more patients

$\star,+F$ eatures found to be significantly different between groups.

$\star \star$ Pulse and respiration rate were only measured in 248 and 250 , respectively, of the study patients.

also suggests that we are unlikely to have missed much significant infection associated with more serious illness.

The aetiology study was only conducted over six winter months when viruses are more common. This may explain why systemic symptoms were more common in the patients who consulted in the winter. It also coincided with a four yearly cycle of mycoplasma infection. ${ }^{16}$ Care therefore needs to be taken in extrapolating the findings to the whole year.

\section{IDENTIFICATION OF PATHOGENS}

There are few data regarding the role of bacterial and atypical infection in acute bronchitis. Previous studies have largely focused on viruses which occurred in about one quarter of patients. ${ }^{12}{ }^{17}$ Melbye et al reported atypical pathogens in $5 \%$ of 393 previously well adults who consulted with both upper and lower respiratory symptoms. ${ }^{18}$ Only four of 67 patients with acute bronchitis had bacterial infection, all pneumococcal. ${ }^{19}$

This study, the first using traditional and newer microbiological investigations, has shown that the symptoms of acute bronchitis, or similar definitions, in previously well adults are related to bacterial, atypical, and viral respiratory pathogens. Specimen collection and follow up in the community were excellent. The association between the detection of bacterial and atypical pathogens and raised CRP levels and chest radiographic changes, together with the marked seasonal pattern, suggest that the pathogens we detected were relevant to the acute illness, causing infection rather than just colonisation.

Bacterial pathogens were found in over $25 \%$ of patients with Streptococcus pneumoniae being the most common followed by Haemophilus influenzae and $M$ catarrhalis. Atypical pathogens were as common as bacterial pathogens with $C$ pneumoniae occurring in $17 \%$ and $M$ pneumoniae in $7 \%$. Viral pathogens, most commonly the influenza viruses, were found in one fifth of patients and were not infrequently associated with bacterial and atypical pathogens.

The bacteria we identified are those typically associated with community acquired lower respiratory tract infection (LRTI) and pneumonia. ${ }^{70}$ Ampicillin resistant bacterial pathogens were isolated from only five patients (H influenzae (2), $M$ catarrhalis (3)), which suggests that antibiotic resistance is not a problem in this population and hence there is little need to use newer antibiotics such as fluoroquinolones.

Our study coincided with a national epidemic of mycoplasma ${ }^{16}$ which explains the much higher incidence of this organism than we have previously reported for LRTI. ${ }^{7}$ Although this emphasises the importance of GPs knowing current seasonal trends in common infections, the use or choice of antibiotic did not relate to outcome in our study. Such up to date epidemiological information is available from the Public Health Laboratory Service website (www.phls.co.uk).

There are few data on $C$ pneumoniae as a respiratory pathogen in Britain but studies elsewhere have implicated it in 5-15\% of LRTI and pneumonia, ${ }^{21}$ and routine treatment with macrolides has been recommended. ${ }^{22}$ We have previously found $C$ pneumoniae infection in $14 \%$ of adults with LRTI, ${ }^{8}$ a similar figure to the $17 \%$ we report here. In this study primary $C$ pneumoniae infection was not associated with 
Table 3 Pathogens detected and their interrelationships

\begin{tabular}{|c|c|c|c|c|c|c|c|}
\hline & Total & $\begin{array}{l}S \\
\text { pneumoniae }\end{array}$ & $\begin{array}{l}H \\
\text { influenzae }\end{array}$ & $\begin{array}{l}\text { M } \\
\text { catarrhalis }\end{array}$ & $\begin{array}{l}M \\
\text { pneumoniae }\end{array}$ & $\begin{array}{l}\text { C } \\
\text { pneumoniae }\end{array}$ & Viral $^{\star}$ \\
\hline Bacterial (82) & 82 & 54 & 31 & 7 & 5 & 15 & 17 \\
\hline$S$ pneumoniae & 54 & 54 & 9 & 0 & 4 & 10 & 11 \\
\hline H influenzae & 30 & 9 & 30 & 0 & 1 & 6 & 4 \\
\hline$M$ catarrhalis & 7 & 0 & 1 & 7 & 0 & 1 & 2 \\
\hline Atypical (75) & 75 & 14 & 7 & 1 & 23 & 55 & 10 \\
\hline M pneumoniae & 23 & 4 & 1 & 0 & 23 & 3 & 4 \\
\hline$C$ pneumoniae & 55 & 10 & 6 & 1 & 3 & 55 & 6 \\
\hline Viral (61) & 61 & 11 & 4 & 2 & 4 & 6 & 61 \\
\hline
\end{tabular}

^Details of viruses detected in text.

Table 4 Relationship between GPs'clinical assessment of the presence of infection warranting antibiotics, the presence of bacterial and/or atypical pathogens, and the prescription of an antibiotic

\begin{tabular}{lcl}
\hline $\begin{array}{l}\text { GPs' clinical assessment of whether } \\
\text { antibiotics are warranted }(n=316)\end{array}$ & $\begin{array}{l}\text { Antibiotic prescribed at first } \\
\text { consultation, } n(\%)\end{array}$ & $\begin{array}{l}\text { Bacterial and/or atypical } \\
\text { pathogens identified, } n \text { (\%) }\end{array}$ \\
\hline Definitely warranted (36) & $36(100 \%)$ & $22(61 \%)$ \\
Probably warranted (125) & $125(100 \%)$ & $51(41 \%)$ \\
Probably not warranted (91) & $18(20 \%)$ & $38(42 \%)$ \\
Definitely not warranted (64) & $2(3 \%)$ & $26(41 \%)$
\end{tabular}

indirect evidence of infection and the outcome was not improved by choosing an antibiotic suitable for atypical pathogens, a finding reported previously. ${ }^{83}{ }^{24}$ In LRTi $C$ pneumoniae may simply initiate events for secondary and more clinically relevant respiratory infection; co-pathogens, mostly bacterial, were present in more than $25 \%$ of our cases and have been reported frequently before. ${ }^{9}{ }^{25}$

Influenza virus infection was found in 23 patients $(8 \%)$, only five of whom consulted within two days of developing symptoms and, hence, at a time that neuraminidase inhibitors may have had a beneficial effect. ${ }^{26}$ This suggests that there would have been no logical role for antiviral therapy in our patients.

USE OF INVESTIGATIONS BY GPS

The use of investigations in primary care varies considerably in Europe, being lowest in the UK. ${ }^{27}$ It would be helpful to know if investigations would help GPs to decide on prescribing of antibiotics.

Most doctors would regard chest radiographic changes consistent with infection as an indication for antibiotic treatment in a patient with acute lower respiratory tract symptoms. The association between focal chest signs on examination and chest radiographic changes supports our previous experience that these physical signs have some value in identifying patients who may have abnormal radiographs. ${ }^{72}$ However, it seems doubtful that an urgent chest radiograph in every previously well adult with acute lower respiratory tract symptoms is of any practical value in management as only $6 \%$ of the patients had radiographic pneumonia and about half of our patients with changes on the chest radiograph recovered without receiving antibiotics. In only two instances did the doctor call back the patient and institute antibiotic treatment after receiving the chest radiographic report; one of these patients also had persisting symptoms and signs. In a previous study we found that only $3 \%$ of patients treated for LRTI were recalled by their doctor because of the initial investigation results. ${ }^{7}$

Guidelines for requesting a chest radiograph are being prepared for GPs to facilitate the early detection of lung cancer. Presentation with LRTi was not a useful pointer in this respect for our patients. A shadow suspicious of malignancy was reported on two chest radiographs but was not confirmed on subsequent investigations.

It has been suggested that rapid measurement of CRP levels may be a useful guide to bacterial infection and antibiotic therapy. ${ }^{28} \mathrm{We}$ found that high CRP levels were related to bacterial or atypical infection but not to outcome, which suggests that knowing the result is unlikely to influence management and outcome. Indeed, it may paradoxically increase unnecessary antibiotic prescribing.

\section{OUTCOME IN RELATION TO PATHOGENS AND}

MANAGEMENT

In this observational study the outcome did not relate to the presence of bacterial or atypical pathogens or to prescribing antibiotics to

Table 5 Relationship between outcome (as measured by reconsultation for the same symptoms within 4 weeks) and patient groups, antibiotic use at initial consultation, and direct and indirect evidence of infection

\begin{tabular}{|c|c|c|c|}
\hline & Reconsulted & Did not reconsult & $\begin{array}{l}p \text { value if } \\
\text { relevant }\end{array}$ \\
\hline $\begin{array}{l}\text { All patients over one year ( } \mathrm{n}=621 \text {; reconsultation data on } 17 \\
\text { not known) }\end{array}$ & $114(18 \%)$ & $507(82 \%)$ & \multirow{18}{*}{0.09} \\
\hline Prescribed antibiotics & $64(56 \%)$ & $50(44 \%)$ & \\
\hline Not prescribed antibiotics & $257(51 \%)$ & $250(49 \%)$ & \\
\hline Patients investigated in detail ( $\mathrm{n}=313 ; 3$ not known) & $59(19 \%)$ & $254(81 \%)$ & \\
\hline Prescribed antibiotics & $36(61 \%)$ & $23(39 \%)$ & \\
\hline Not prescribed antibiotics & $145(57 \%)$ & $109(43 \%)$ & \\
\hline \multicolumn{4}{|l|}{ Indirect evidence of infection ( 3 not known) } \\
\hline CRP high $(\geqslant 50 \mathrm{mg} / \mathrm{l})$ & $8(16 \%)$ & $41(84 \%)$ & \\
\hline CRP not high & $51(19 \%)$ & $213(81 \%)$ & \\
\hline Infection changes on chest radiograph & $13(28 \%)$ & $34(72 \%)$ & \\
\hline No infection changes on chest radiograph & $41(17 \%)$ & $198(83 \%)$ & \\
\hline \multicolumn{3}{|l|}{ Direct evidence of infection ( 3 not known) } & \\
\hline Bacterial/ atypical pathogens identified (group 1) & $28(21 \%)$ & $107(79 \%)$ & \\
\hline Viral or no pathogens identified (group 2) & $31(17 \%)$ & $147(83 \%)$ & \\
\hline \multicolumn{3}{|l|}{ Antibiotic use and infection groups } & \\
\hline Group 1 (antibiotic received) & $21(26 \%)$ & $61(74 \%)$ & \\
\hline Group 1 (no antibiotic received) & $7(13 \%)$ & $46(87 \%)$ & \\
\hline Group 2 (antibiotic received) & $15(17 \%)$ & $84(83 \%)$ & \\
\hline Group 2 (no antibiotic received) & $20(25 \%)$ & $60(75 \%)$ & \\
\hline
\end{tabular}


which the pathogen should respond. We have previously found reconsultation not to relate to use of antibiotics at the index consultation. ${ }^{15} \mathrm{~A}$ systematic review of the role of antibiotics for acute bronchitis similarly concluded that, taken overall, antibiotics did little to influence the natural history of the symptoms and any minor benefit in individual groups was offset by side effects to the antibiotics. ${ }^{3}$

However, it is inappropriate and unhelpful to suggest that antibiotics will help no patients with acute bronchitis or LRTi, ${ }^{29}$ as there will clearly be a cohort of patients for whom antibiotics will be beneficial. The difficulty is in identifying such patients in the primary care setting and the challenge is to come up with practical and evidence based guidance that may be useful to the GP. Unfortunately our study did not find that, overall, clinical judgement or specific symptoms or signs related to outcome. However, the strong association between focal chest signs and radiographic pneumonia suggests that the practice of many GPs of prescribing antibiotics to patients with LRTi when such signs are present is well founded. ${ }^{2}$

In conclusion, this study has confirmed that LRTi is a very common reason for previously well adults to consult their GP and hence is a condition for which agreed management would be useful. LRTi is caused by infection. Bacterial, atypical, and viral pathogens can be identified in more than half the cases and indirect evidence of infection in a quarter. With the exception of focal chest signs, neither the findings on physical examination nor the GP's global assessment reliably identifies patients with evidence of infection. The usual practice of undertaking few routine investigations appears well founded. Our observations on the outcome of LRTi supports the view that antibiotics generally, or even when directed specifically at particular pathogens, do not influence the outcome in most patients, most of whom will recover spontaneously. We are most grateful to the following who all contributed to the success of the study in different ways: Peter Pavier, Suresh Patel, Jichard Howard, Mike Elliott, Gina Bajek, Fiona McCracken, Jacqueline Pidcock and Andrew Flewitt (general practitioners),
Loraine Hayles, Christina Roebuck and Elizabeth Everitt Loraine Hayles, Christina Roebuck and Elizabeth Everitt
(research practice nurses), Sallie Porter and Denise Clegg (research practice nurses), Sallie Porter and Denise Clegg
(practice managers) and their staff, Robert Cave and Joanne (practice managers) and their staff, Robert Cave and Joanne
Palfryman at Nottingham Public Health Laboratory, Stephanie Palfryman at Nottingham Public Health Laboratory, Stephanie nated the microbiology specimens, and Dr Margaret Sillis, Mycoplasma Reference Laboratory, Norwich, UK who performed specialised mycoplasma serology. We also thank the Departments of Biochemistry, Radiology, Microbiology, M Sarah Pacey of Pharmacy, and Mr Ben Masterson of the Finance Department for their help and cooperation.

The study was supported by a project grant from the British Lung Foundation and the Cooperative Insurance Society of Manchester.

Conflict of interest: none.

1 Office of Population Censuses and Surveys. Morbidity statislstudy 1991-1992. Series MB5,3. London: HMSO, 1995.

2 Macfarlane JT, Holmes WF, Macfarlane RM, et al. Contemporary use of antibiotics in 1089 adults presenting with acute LRTi in general practice in the UK: implications for developing management guidelines. Respir Med 1997;91: 427-34.
3 Fahey T, Stocks N, Thomas T. Quantitative systematic review of randomised controlled trials comparing antibiotic with placebo for acute cough in adults. BMF 1998;316: 906-10.

4 Macfarlane JT, Holmes WF, Macfarlane RM. Reducing reconsultations for acute LRTi with an information leaflet: a randomised controlled study of 1006 patients in primary care. Br f Gen Pract 1997;47:719-22.

5 Macfarlane JT, Holmes WF, Macfarlane RM, et al. Influence of patients' expectations on antibiotic management of acute LRTi in general practice: a questionnaire ment of acute LRT1 in general
study. BMf 1997;315:1211-4.

6 Macfarlane JT. Lower respiratory tract infection and pneumonia in the community. In: European Perspective on Community Acquired Pneumonia. Semin Respir Infect 1999;14:151-62.

7 Macfarlane JT, Colville A, Guion A, et al. Prospective study of aetiology and outcome of adult lower respiratory tract infection in the community. Lancet 1993;341:511-4.

8 Macfarlane J, Prewett J, Rose D, et al. A prospective, case control study of the aetiology of community acquired lower respiratory tract infections in adults who fail to improve with initial antibiotics. BMF 1997;315:1206-10.

9 Kauppinen M, Herrva E, Kujala P, et al. The aetiology of community acquired pneumonia among hospitalised patients during a $C$ pneumoniae epidemic in Finland. $\mathcal{F}$ Infect Dis 1995;172:1330-5.

10 Ortqvist A, Hedlund J, Hofer M, et al. Effectiveness of the pneumococcal vaccination in the prevention of pneumonia in middle aged and elderly persons: a prospective, multicentre, double blind, placebo controlled trial of the 23 valent pneumococcal capsular polysaccharide vaccine. Lancet 1997;351:399-403.

11 Monto SA, Napier JA, Metzner HI. The Tecumseh study of respiratory illness. 1. Plan of study and observations on syndromes of acute respiratory disease. Am $\mathcal{F}$ Epidemiol 1971;94:274-9.

12 Nicholson KG, Hammersley V, Cancio E. Risk factors for lower respiratory complications of rhinovirus infections in elderly people living in the community: prospective cohort study. BMF 1996;313:1119-23.

13 Del Mar C. Sore throats and antibiotics. BMF 2000;320: 130-1.

14 Holmes WF, Macfarlane RM, Lewis S, et al. Physical signs, symptom resolution and antibiotic prescribing in acute lower respiratory tract illness (LRTi): a prospective study in primary care. Br f Gen Pract 2000 (in press).

15 Holmes WF, Macfarlane JT, Macfarlane RM, et al. The influence of antibiotics and other factors on reconsultation for acute LRTi in primary care. Br f Gen Pract 1997;47:815-8.

16 Editorial. Recent increases in influenza and other respiratory infections. CDR Report 1999;9:17-20.

17 Monto SA, Ullman BM. Acute respiratory illness in an American community. The Tecumseh study. fAMA 1974; 227:164-9.

18 Melbye H, Kongerud J, Vorland L. Reversible airflow limitation in adults with respiratory infection. Eur Respir $\mathcal{F}$ 1994; 7:1239-45.

19 Melbye H, Berdal BP, Straume B, et al. Pneumonia-a clinical or radiographic diagnosis. Scand F Infect Dis 1992;24: 647-55.

20 Woodhead MA, Macfarlane JT, McCracken JS, et al. Prospective study of the aetiology and outcome of pneumonia in the community. Lancet 1987; ;:671-4.

21 Torres A, El Ebiary M. Relevance of Chlamydia pneumoniae in community acquired respiratory infections. Eur Respir $\mathcal{F}$ 1993;6:7-8.

22 Wort SJ, Rogers TR. Community acquired pneumonia in elderly people. $B M \mathcal{F}$ 1998;316:1690.

23 Kauppinen MT, Saikku P, Kujala P, et al. Clinical picture of community acquired Chlamydia pneumoniae pneumonia requiring hospital treatment. Thorax 1996;51:185-9.

24 File TM, Segreti J, Dunbar L, et al. A multicentre, randomised study comparing the efficacy and safety of intravenous and/or oral levofloxacin versus ceftriaxone and/or cefuroxime axetil in treatment of adults with community acquired pneumonia. Antimicrob Agents Chemother 1997;41:1965-72.

25 Woodhead MA. Community acquired pneumonia in elderly patients: addition of erythromycin is not currently justified. BMF 1998;317:1524.

26 Hayden FG, Osterhaus A, Treanor JJ, et al. Efficacy and safety of the neuraminidase inhibitor zanamivir in the treatment of influenza virus infections. N Engl F Med 1997; 337:874-80

27 Woodhead M, Gialdroni-Grassi G, Huchon GJ, et al. Use of investigations in lower respiratory tract infection in the community: a European study. Eur Respir 7 1996;9:1596600 .

28 Husebekk A, Hansson L-O. C reactive protein in clinical practice. 2nd ed. Oslo: Nycopharma AS, 1999

29 Gonzales R, Sande M. What will it take to stop physicians from prescribing antibiotics in acute bronchitis? Lancet 1995;345:665-6. 